\title{
Healthy Eating for Elders: Sixteen Savory Snacks ${ }^{1}$
}

\section{Jennifer Hillan ${ }^{2}$}

Here are some snack ideas that are not only easy to prepare, they are

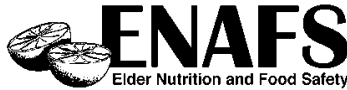

healthy too! Keep some of these choices handy for the next time you have the snacking urge.

1. Zucchini strips dipped in low-fat ranch dressing or plain yogurt

2. Frozen banana (peel before freezing)

3. $1 / 2$ bagel topped with fruit preserves

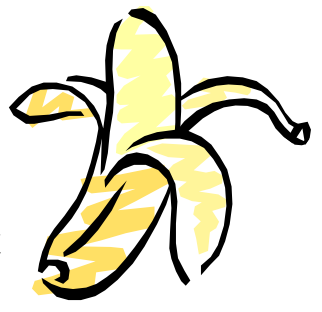

4. $1 / 4$ cup dried mixed fruit

5. Graham crackers topped with peanut butter

6. 1 cup buttermilk

7. $1 \frac{1}{2}$ ounces low-fat string cheese

8. Homemade popsicle

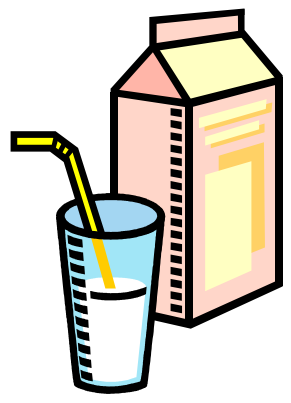
(made with your favorite fruit or vegetable juice)

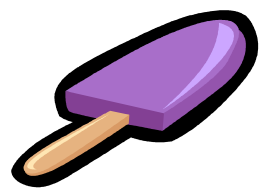

10. 1 cup low-fat yogurt

11. $1 / 2$ cup sliced cucumbers and tomatoes with low-fat Italian dressing or plain yogurt

12. Pita bread and hummus (chickpea dip)

13. Slice of whole wheat toast with margarine and a pinch of sugar and cinnamon

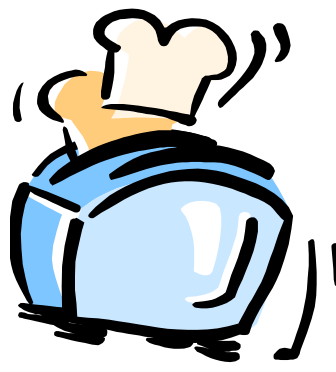

14. Tortilla topped with melted cheese

15. $1 / 2$ cup melon cubes

16. $3 / 4$ cup low-sodium vegetable juice with 3 to 4 wheat crackers

1. This is document FCS 8697-ENG, one in a series of the Department of Family, Youth and Community Sciences, Florida Cooperative Extension Service, Institute of Food and Agricultural Sciences, University of Florida, Gainesville, FL 32611. Publication date: February 2005, This leaflet was developed with funding from the Florida Department of Elder Affairs in partnership with state, county, and local agencies. Please visit the EDIS Web site at http://edis.ifas.ufl.edu

2. Jennifer Hillan, MSH, RD, LD/N, former ENAFS nutrition educator/trainer, Department of Family, Youth and Community Sciences, University of Florida, Gainesville, FL 32611. Reviewed by Linda B. Bobroff, PhD, RD, LD/N, professor, and Leigh Ann Martin, MESS, former ENAFS project coordinator, University of Florida. 